\title{
Preventing dysfunction and improving policy advice: the role of intra-departmental boundary spanners
}

\section{Gemma Carey}

Dr Carey is an NHMRC Research Fellow and Senior Lecturer with UNSW Canberra. She holds a $\mathrm{PhD}$ in social policy and population health from the University of Melbourne In addition to her academic research, she runs a policy forum - the Power to Persuade (PTP) (an annual symposium and blog). PTP is aimed at improving the relationships between policymakers, academics and the community sector. Running since 2011, PTP is sponsored by the Victorian Government and a range of NGOs and peak bodies (www.powertopersuade.org.au)

\section{Fiona Buick}

Dr Buick is an Assistant Professor at the University of Canberra in Public Management. She was awarded a PhD in Management from the University of Canberra in June 2012. Her thesis focused on the impact of organisational culture on joined-up working in the Australian Public Service (APS).

\section{Melanie Pescud}

Melanie is a Research Fellow in the RegNet School of Regulation and Global Governance. Prior to joining RegNet she spent eight years in Perth at the University of Western Australia (UWA). Across this time she worked at the Graduate School of Management, UWA Business School, and the School of Sport Science, Exercise and Health.

She has worked in the areas of child obesity prevention, health promotion, seniors' mental health, alcohol warning statement labelling, alcohol use in teenagers, nutrition literacy, Indigenous health behaviour, workplace health promotion and evaluation, health policy development, and qualitative research methodologies.

\section{Eleanor Malbon}

Eleanor holds a Combined Bachelor of Arts and Science from the ANU with first class honours in Human Ecology. Her specialisation within Human Ecology is system dynamics, soft systems methods and collaborative conceptual modelling. At RegNet she works as with Professor Sharon Friel to provide system dynamics expertise to a number of health equity related research projects. She is passionate about teaching and she has tutored for multiple courses within the Fenner School of Environment and Society, and currently tutors for the course Complex Environmental Problems in Action. She also convenes the Health Equity and Governance Group Forum at RegNet.

\section{Abstract}

This is the author manuscript accepted for publication and has undergone full peer review but has not been through the copyediting, typesetting, pagination and proofreading process, which may lead to differences between this version and the Version of Record. Please cite this article as doi: 10.1111/1467-8500.12213.

This article is protected by copyright. All rights reserved. 
It is well established in the public management literature that boundary spanners - people or groups that work across departments or sectors - are critical to the success of whole of government and joined-up working. In studying recent, unprecedented changes, to central government agencies in the Australian context our research identified that intra-departmental boundary spanners also play a critical role in for functioning, particularly during re-structuring. While most contemporary literature in public management concentrates on boundaries formal organisational entities (departments, agencies, sectors) boundaries also exist within departments. Our research has found that without dedicated intra-departmental boundary spanners significant role confusion and dysfunctional practices arise. In turn, this has serious implications for the quality of policy advice given to cabinet.

Further research needs to be undertaken into both the role of intra-departmental boundary spanners and how to nurture and manage the practice of intra-departmental boundary spanners. This is especially the case if changes in Australia represent a fundamental shift more broadly in the way central government agencies operate.

\section{Introduction}

Central government agencies tend to exist in a state of flux, dependant on political and policy demands of the day $(6,1997 ;$ Buckley, 2006). In Australia, for example, special task forces are frequently assembled and then disassembled within central agencies such as the Department of Prime Minister and Cabinet (PM\&C) (and, to a lesser extent, Treasury and Finance) in order to action policy decisions. Similarly, machinery of government changes are common in the public sector. Although these changes frequently involve the merging and de-merging of functional departments, they can also impact central agencies. For example, whole units can be integrated or extracted from agencies/departments such as PM\&C. In Australia, this has been the case with the Office for Women which has been moved in and out of PM\&C for some time (Bacchi and Eveline, 2010). This trend is reflected in other OECD countries, particularly the United Kingdom (UK) (Buckley, 2006).

As Perri 6 (1997, p. 18) argues, reflecting broadly on changes to the organisation of bureaucracies, "functions have been put together and pulled apart many times during the twentieth century in the name of 'rationalisation'. But the particular rationales have often had less to do with synergies of functions or the disappearance of old needs and the emergence of new ones than with the need to give or deny power to particular politicians of cabinet rank". Recent changes to Australian central agencies, particularly PM\&C, exemplify this practice, yet are unprecedented in their scope and potential impact for the operation of government (Boston and Halligan, 2012; Buckley, 2006). These changes may very well represent a fundamental shift in the way central agencies operate, and what is thought to be their purpose and function (Commonwealth Government, 2016).

This article is protected by copyright. All rights reserved. 
Traditionally, central agencies have played an oversight and coordination role - overseeing other departments whose primary responsibility is to deliver, manage or contract service functions (6, 1997; Blackman et al., 2010; Boston and Halligan, 2012; Buckley, 2006). In addition, more power has been concentrated in central agencies in Westminster systems (Aucoin, 2012; Boston and Halligan, 2012). In 2013, when the conservative Abbott government came to power, they fundamentally changed the nature of PM\&C. In order to signal his intent for making inroads into the intractable problem of Indigenous inequality and gender inequality, Abbott appointed himself the Minister for Indigenous Affairs and the Minister for Women (Commonwealth Government, 2016; Senate Estimates, 2013; Strakosch, 2013). This act triggered a major restructure of government departments. Functions related to these ministerial roles were brought into PM\&C. While the Office for Women (under various guises) has come and gone from PM\&C, never in the history of the Australian Government has a large service-delivery, or line, agency such as Indigenous Affairs been moved into a central agency (Commonwealth Government, 2016). This change - triggered by a political decision - resulted in over 800 staff being moved into PM\&C (Senate Estimates, 2013). This change has meant that service-delivery staff across Australia (including remote areas) are now overseen by PM\&C, representing a fundamental shift in the role of this central agency (Senate Estimates, 2013). This is further supported by recent changes whereby responsibility for the implementation of the Australian National Disability Insurance Scheme in the Victorian Government has been placed in the Department of Premier and Cabinet (DPC, 2013).

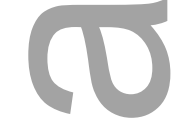

In this paper, we explore how this change affected both the functioning of PM\&C and Indigenous Affairs. While this case raises a range of issues which warrant investigation, including the changing nature of central agencies and their ability to fulfil the coordination and whole of government functions subscribed to them, in this paper we focus exclusively on the role of boundary spanners. It is well established in the public management literature that boundary spanners - people or groups that work across departments or sectors - are critical to the success of whole of government and joined-up working within a networked policy environment (de Bruijn and Heuvelhof, 1997; Dickinson and Carey, 2016; Keast, 2011; Osborne, 2010; Williams, 2010, 2002). In this paper we explore the role of intra-departmental boundary spanners, specifically due to their central role in bridging across the considerable cultural differences that now exist within PM\&C.

While boundaries are generally conceptualised as existing between formal organisational entities (departments, agencies, sectors) these are, in fact, structural boundaries (6, 1997; de Bruijn and Heuvelhof, 1997; Klijn, 1997; O'Flynn, 2011; Pollitt, 2003). Cultural, and other forms of boundaries, can exist within a single organisational or departmental unit. These typically form due to the emergence of subcultures within organisations and may result in challenges communicating and cooperating across intra-organisational boundaries (Martin, 1992; Schein, 1996). Yet the increasing need to cross boundaries has left scholars with a range of unanswered questions, including what boundaries exist, the extent to which they are movable and the

This article is protected by copyright. All rights reserved. 
driving forces behind crossing boundaries (O'Flynn, 2014). In this paper we aim to advance this literature by examining intra-departmental boundary spanners. We found that significant role confusion and dysfunctional practices can arise when these individuals are removed from organisational structures. In turn, this has negative flow on effects for quality policy advice and action.

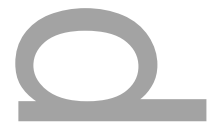

\section{Background}

As Osborne (2010) notes, "the reality of contemporary public service management is that it is an interorganisational and collaborative activity, and requires the governance of complex systems and interorganisational processes". Even within governments, since the 1990s there has been an emphasis on inter-departmental working. That is, that silos exist within governments and need to be bridged. Although, arguably this has been a long-standing concern of governments (6, 1997; O’Flynn, 2011).

With regard to inter-departmental working, O'Flynn $(2014,2011)$ has suggested that there are many ways to organise bureaucracies, including by purpose, function, clientele and geography. Recent experiences in Australia demonstrate that politics can also dictate differentiation. What is challenging, O'Flynn (2011) contends, about how bureaucracies are organised and structured is that "any task naturally contains pieces of each" (p.3). In other words, no matter which way you organise, boundaries will be created and these will require coordination and bridging. A wide range of instruments have been developed to achieve this, including interdepartmental working groups, skill and knowledge development, collaborative working parties, and shared leadership (Carey et al., 2014; Carey and Crammond, 2015). Despite this, the challenges of working across boundaries remain and, as O’Flynn (2014) has suggested, continue to be a fundamental question in public management.

Governments in liberal welfare states like Australia and the UK have implemented continual iterations of structural change as a means to overcome boundary issues (Keast, 2011; O'Flynn, 2014). As noted by the Australian Public Service Commission (2007) "existing public sector institutions and structures were, by and large, not designed with a primary goal of supporting collaborative inter-organisational work" (p.17). Somewhat paradoxically, because we know that structures matter for the creation of boundaries and that "most current structural arrangements act as barriers" (O'Flynn, 2014, p. 29), we presume there is a structural answer to the boundary problem. This is underpinned by the assumption that seeking the right structural form will circumvent issues of coordination and cultural differences. This is evident in the numerous structural arrangements evident in joining-up, including the establishment of project and working groups (Christensen et al., 2015; Christensen and Laegreid, 2007, 2006), one-stop shops and joint teams, through to the more extreme machinery of government changes that

This article is protected by copyright. All rights reserved. 
merge different functional areas together (Talbot and Talbot, 2014). Structural change may assist in some instances, but it can also lead to boundaries being moved rather than crossed (Klaster, 2014)(Klaster, Wilderom and Muntslag, 2014). We will explore these issues in this paper, and the interplay between structure and agency in practice (Dickinson and Sullivan, 2014).

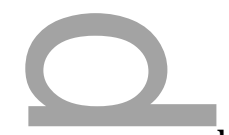

The emergence and increased complexity of policy networks, along with the rising demand for interdepartmental working, has given way to the concept, and analysis, of 'boundary spanners'. Although often discussed in conjunction with the growing complexity of policy networks since the 1990s, the importance of boundary spanners was noted as far back as the 1970s (Aldrich and Herker, 1977; Tushman and Scanlan, 1981). Since this time, boundary spanners have been referred to as linking pins (Leifer and Delbecq, 1978), strategic brokers (Craig, 2004) and entrepreneurs of power (Degeling, 1995; Dickinson and Carey, 2016). Boundary spanners are individuals or groups who work across organisational and sectoral boundaries to broker relationships, cultures and so forth (Williams, 2002). They are increasingly seen as critical to overcoming structural boundaries (LeRoux, 2013; Williams, 2002). Williams (2012) argues there are two major categories of boundary spanner: individuals who have a dedicated role and mandate for working in multi-organisational/multi-sector settings. This group is small in number in the context of the overall public service workforce (Dickinson and Carey, 2016). The second group are individuals who naturally undertake boundary spanning activities in the course of doing their work (i.e. it is not a specified or delineated role). To be classified as a boundary spanner, individuals in both categories should act to:

$\bullet$

Build sustainable and effective relationships and networks

- Communicate and listen 'deeply'

- Understand, empathise with multiple perspectives and resolve conflict

- Build trust and broker solutions between different parties

- Manage through influence and negotiation (Williams, 2002).

This set of skills makes boundary spanners indispensable for overcoming structural barriers, supporting coordination and brokering cultural differences. To date, boundary spanners have been thought to be important for inter-departmental working and cross-sectoral working. In this paper, we explore the importance for boundary spanners in intra-departmental settings, particularly in the wake of structural change.

\section{Methods}

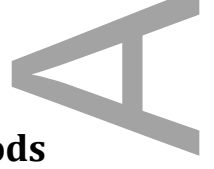

This article is protected by copyright. All rights reserved. 
The aim of the study was to investigate the changing nature of central government agencies and the implications for addressing complex policy problems. This included implications for: crossgovernment working, service delivery, policy design and implementation. The study utilised a case study research design to because it enabled us to investigate these changes in-depth and in their real-life contexts (Yin, 2014). We specifically focused on the changing role of the Department of Prime Minister and Cabinet (PM\&C) due to its recent large-scale change involving bringing together PM\&C, Indigenous Affairs, the Office for Women, and Regulatory Reform and Finance. The research adopted an interpretivist approach; seeking an understanding of how structural changes were experienced in the context of large central agency mergers and acquisitions.

We began with purposive sampling of key individuals within PM\&C areas affected by the change. This sample comprised the senior managers in affected areas. Snowball sampling was then conducted in order to identify participants within PM\&C. Individuals were sought who: (a) had been brought into PM\&C under recent restructuring or (b) had worked in PM\&C prior to (and were present for) recent structural changes. Snowball sampling continued until participants were unable to suggest other potential participants or began to nominate individuals already interviewed. In total, 16 semi-structured interviews were conducted across PM\&C, including 'legacy' (i.e. original PM\&C employees), Indigenous Affairs, the Office for Women and Regulatory Reform and Finance. Participants ranged from deputy departmental secretaries to directors of sections (see Table 1). Interviewing was ceased when participants began to nominate individuals who had already taken part in the study and saturation was reached (i.e. no new themes were emerging).

\begin{tabular}{|c|c|}
\hline Code & Position \\
\hline $\mathbf{P 1}$ & PM\&C Legacy \& Office for Women* \\
\hline P2 & PM\&C Legacy \\
\hline P3 & Indigenous Affairs \\
\hline P4 & Regulatory Reform \\
\hline P5 & Office for Women \\
\hline P6 & Regulatory Reform \\
\hline P7 & PM\&C Legacy \\
\hline P8 & Indigenous Affairs \\
\hline P9 & PM\&C Legacy \\
\hline
\end{tabular}

This article is protected by copyright. All rights reserved. 


\begin{tabular}{|ll}
\hline P10 & Indigenous Affairs \\
\hline P11 & Indigenous Affairs \\
$\mathbf{P 1 2}$ & Indigenous Affairs \\
$\mathbf{P 1 3}$ & Indigenous Affairs \\
$\mathbf{P 1 4}$ & Indigenous Affairs \\
$\mathbf{P 1 5}$ & Indigenous Affairs \\
\hline
\end{tabular}

*Participant changed roles

Table 1. Participants

Semi-structured interviews were recorded (with the exception of participant 2, on request) and transcribed verbatim. Themes covered in the interviews included: the rationale for central agency changes, the experiences of implementing the change, organisational planning and change management, and implications for policy design, implementation and outcomes. Data were analysed by three of the authors using a thematic approach (Blaikie, 2010). 'Like' data were grouped together to form categories and subcategories. These categories were developed into more substantive themes, by linking and drawing connections between initial categories and hypothesising about consequences and likely explanations for the appearance of certain phenomena (Strauss, 1987). This was done through discussion between the team. In the refining of themes for publication, selective coding was carried out, whereby transcripts were revisited with the explicit intent of finding further linkages and connections between the central issue being explored and other themes.

\section{Findings}

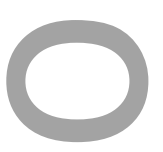

Traditionally, PM\&C has had policy 'shadow teams' for each portfolio and policy area across government. The role of these teams was to coordinate briefings, advice and so forth from different line-agencies and portfolios with consideration for the needs of the government as a whole, and generate briefs for the Prime Minister accordingly. Additionally, according to our participants, the shadow teams also managed relationships and spanned the different cultures between $\mathrm{PM} \& \mathrm{C}$ as a central coordinating agency and line agencies that delivered services. This was a necessary function because central agencies are driven by the Cabinet and politics and need to be fast-paced and responsive to government. They also need to be able to play a coordination and oversight function to ensure the advice provided is accurate and in line with the government's broader agenda. In contrast, line agencies manage implementation; as such, they operate at a different pace and are concerned with different matters, such as contract

This article is protected by copyright. All rights reserved. 
management and program design and delivery. In addition, they tend to have a more narrow orientation, focused on their particular functional area. As explained by one participant:

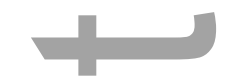

Line agencies work in days and weeks. PM\&C works in hours. [In PM\&C] you have to be able to ring somebody up and say 'I'm sending out a Cabinet [brief]' ... Because of the timeframes involved in the Cabinet processes... Whereas a lot of the guideline work, or a lot of the program implementation work [done by line agencies], is iterative. It's developing a series of products whether it be guidelines, whether it be help manuals for the providers... (P01)

The shadow teams in PM\&C fulfilled a boundary-spanning role between these divergent worlds: "PM\&C has a central policy team that shadows a portfolio and looks at independently, drawing together everyone's perspectives" (P10). Hence, these teams dealt with differences in perspective, culture and needs between line agencies and the central agencies, particularly PM\&C:

PM\&C, the 'Legacy PM\&C' [i.e. PM\&C prior to the introduction of the new units] involves the act of shadowing. ...So previously there'd be an area that would oversight the Deregulation, Area of Finance or the Women's area or the Indigenous Affairs area.... The Prime Minister and the Secretary [of PM\&C] might want something different from your Portfolio Minister or your Secretary. [Their role was] to be able to understand ... points where the relationship may break down. Points where there will be differences of understanding or differences of approach. Points where there'll be policy differences or implementation differences or differences in outcomes (P01).

Despite their integral boundary spanning role, these 'shadow teams' were removed following the integration of Indigenous Affairs, the Office for Women and the Regulatory Group in PM\&C. One participant noted: "It was interesting the way in which the act of shadowing was then dissolved for those areas that got brought into PM\&C." (P01). It was presumed that once the structural boundary (i.e. the existence of separate departments) was removed, shadow teams or boundary spanners - were redundant. A participant from Indigenous Affairs explained:

The shadow unit was removed for Indigenous Affairs. There is no independent advice going to $\mathrm{PM} \& \mathrm{C}$, no team of people whose job it is to interrogate what we do. The decision was taken that you wouldn't have a sort of 'secret spy unit' shadowing within the same department. (P10)

This issue was exacerbated by the lack of investment in addressing the skill and knowledge gaps created by the removal of the shadow teams. For example, little guidance was given to those moving into PM\&C on how the cultures, timelines and demands differed between line agencies

This article is protected by copyright. All rights reserved. 
and central agencies. In effect, staff moving into PM\&C took up the responsibilities of the shadow teams, in addition to their line-agency roles:

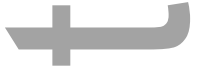

So the oversight areas were removed. So also there was no kind of an institutional memory to guide [those coming into PM\&C from line agencies] with ... how you'd do these things in PM\&C but they were then expected to fulfil dual roles. So it was you're being a line agency but you're also being a central agency. I think someone may have sent them a couple of our briefings as an example. But there was no PM\&C person that kind of walked them through (P01)
\end{abstract}

We didn't put enough resources into the move at the start. We didn't realise how big an organisational change it would be... managing changes in culture, the functions, the role. No we didn't do that well, I don't think we invested in it. (P10)

The act of removing shadow teams suggests that once the structural barriers between departments had been removed, it was presumed that staff would adjust and have the capabilities necessary to both work together and bridge the central and line agency worlds. However, a clear articulation of shared outcomes was lacking, which has been identified as an important enabler for effective cross-organisational and cross-governmental working (Blackman, 2014; Blackman et al., 2010).

These issues were further exacerbated by the new PM\&C being geographically dispersed across the country, thus impeding knowledge transfer within the new agency “... because Indigenous Affairs also had a number of [offices]. It had a whole network. So even if [the Central office] got ... all the information, how do you get that to the people in Melbourne office? Or the Thursday Island office? Or the Broome office?" (P01). This supports our observation from the literature that boundaries are perceived to be primarily structural (that can, in turn, lead to cultural boundaries) and therefore can be overcome by structural change alone (i.e. merging departments together). As one participant noted, however, "You can bring in certain functions together but the mindset at the top doesn't change from 'we're a central agency'” (P10). As noted above, the challenges associated with cultural adjustment for incoming agencies was amplified by the dispersed geographical locations of Indigenous Affairs across the country.

The removal of the shadow teams created unusual departmental briefing arrangements. The shadow teams acted as official boundary spanners between PM\&C and line agencies. Yet, when these functions were brought into $\mathrm{PM} \& \mathrm{C}$, retaining these boundary spanners was seen as unnecessary and potentially dysfunctional, as represented in them being referred to as a "secret spy unit" (P10) within PM\&C. In contrast, we argue that this group's role needed to be formally re-shaped as an intra-departmental boundary-spanning group who performed an important

This article is protected by copyright. All rights reserved. 
bridging function. By failing to retain and re-shape these boundary spanning roles, far more dysfunctional practices emerged. For example, the absence of these roles meant that staff from line agencies were required to prepare briefs for both their Portfolio Ministers and the Prime Minister. In doing so, they had to generate a line agency perspective, then critique their own work from a central agency perspective. This was an issue because Ministers and the Prime Minister were said to have different briefing needs:

They've just got completely different needs. And [the Minister for Indigenous Affairs] has ... spent all his life living in northern Australia, and he understands Indigenous Affairs through daily contact with remote communities. The Prime Minister's dealing with constitutional recognition. So we have to be able to support two conversations. Both of them have to be authentic, and they are important conversations ... [this requires] the bureaucratic skill of being able to condense something right down. And produce two very different products. Because what Nigel Scullion [Minister for Indigenous Affairs] wants is practical stuff, on the ground, happening now. What the Prime Minister needs is more in the upper echelon of the public policy world (P02)

Participants used the metaphor of changing hats to explain the experience of meeting these different briefing demands:

So it's a very high level approach and you're asking people who never had to do that for somebody to put on a very different hat for half their day, to switch hats constantly and take very different perspectives in their work (P01).

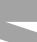

So we, and to sort of illustrate that, for example, if the Minister for Women is bringing forward a submission to Cabinet we prepare that submission, we do the briefing for the Minister to speak at Cabinet and then we put our hat as Department of Prime Minister and Cabinet [on] to provide briefing to the Prime Minister which may be critical of the Minister for Women's submission ... strengthened or where the risks are for the Prime Minister or government particularly... I imagine actually doing that 'hat thing' because that helps you get into the mindset of that. And also being very clear and articulating that with the staff about this bifurcated role. So if you understand that's what you're doing it makes it easier then to identify where the conflict or tension might emerge. Being a lawyer, having worked in the sort of environment where you have to have a Chinese wall sometimes, I find then that it's easier for me to manage that... It's easy for me to envisage that, it doesn't mean that it's necessarily easy each time to deal with the particular tensions. Sometimes I have to go hang on I'm not looking at this like PM\&C (P05).

Another participant used the metaphor of contagion:

It's a bit odd sometimes if Minister Scullion has an idea, you know the idea's drafted by Indigenous Affairs group. Sometimes in social policy we'll do the brief for the Prime Minister to sort of get that separation of contagion and we do that now more from a social policy perspective because we no longer have a discrete Indigenous Affairs [shadow] unit (P09)

Scharpf (1989) referred to this situation as a misfit between the empirical structure of an organisational and the prescriptive task structure. Applied to $\mathrm{PM} \& \mathrm{C}$, this meant that the organisation was no longer fit-for-purpose in the sense that the primary role of PM\&C is to coordinate and ensure the quality of policy advice at the centre of government. The inclusion of

This article is protected by copyright. All rights reserved. 
service-delivery and other functional areas, and the procedural loss of the official boundary spanners in the form of the shadow teams, diminished the ability for PM\&C to fulfil this role.

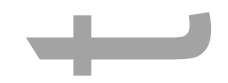

In addition to creating odd, and potentially dysfunctional, work practices we found that the difficulties involyed in briefing both to Ministers and the Prime Minister was potentially detrimental to the quality and robustness of the policy advice being given to the Prime Minister's Office. The dual role of staff meant that they were required to simultaneously deliver policy advice and critique it. This was identified as problematic because our participants recognised that staff with line agency responsibilities could not critique their own work with the same level of independence and impartiality as the former shadow units. Regardless of their ability to 'swap hats', 'prevent contagion' or 'keep Chinese walls', in critiquing the briefs and advice they create to serve the needs of their Minister they risk damaging relationships and their career advancement (i.e. by potentially being seen as undermining the aims of the Minister). As Perri 6 (1997, p. 22) argues, "Few gain in career terms from questioning the interests of their department...[or are] promoted for cutting their own budgets ...[or] thanked by their ministers for negotiating away any of their power". This highlights the integral role that the previous shadow team played as being able to enhance the quality of policy advice provided by line agencies. Their role as boundary spanners meant that could mitigate poor policy advice in ways that staff in line agencies could not. This point was well articulated by a senior staff member in Indigenous Affairs:

Occasionally central agency intervention is welcome. It's hard for a line agency to argue with a Minister... If they want to do something stupid you're out of options for how you influence him. PM\&C was an influencer, they were a central body but we've blunted that instrument... The beauty of the central agencies are that they are nimble... have oversight and can present alternatives. The merger has certainly compromised this in the Indigenous Affairs space (P10).

Ministers, as Perri 6 (2007; 39) suggests, speak from their departmental or portfolio perspective, "defending their departmental turf and, over time, come to regard coordination as a game of winners and losers. In the executive, the Treasury and the central policy staff are expected to coordinate but they often find themselves fighting departments". Bringing the portfolio of another minister into PM\&C has the potential to heighten this tension: "By bringing it together in PM\&C you then bring the Minister into PM\&C and that relationship... the dynamics of that can get pretty ugly" (P10). As suggested by this observation, the removal of intraorganisational boundary spanners could potentially have negative effects on the quality of advice that is provided to the top of government. These issues highlight the important role that boundary spanners play, not only in bridging departmental or functional boundaries, but in upholding the quality of policy advice provided to government. Despite the general view that eradicating the shadow teams diminished effectiveness, we did find an exemplar where boundary spanning was evident and enhancing effectiveness in some areas.

This article is protected by copyright. All rights reserved. 
In our study we found one example of effective intra- and inter-departmental boundary spanning. One participant, who was a senior manager towards the end of their career in Indigenous Affairs, had formulated their own role. This role, and the participant's practice, encapsulates William's (2002) characteristics of a competent boundary spanner. This participant described the role they created within the newly merged Indigenous Affairs PM\&C unit:

So, what's happened is in the department we have each of the divisions and - I didn't want to do a division; I have no interest in being caught up in administration just because I'm towards the end of my career and I'm thinking about, "How do you tweak systems?" ... So, I am completely respectful of my colleagues running their own business and then I only come in as it intersects if an issue arises that could be politically sensitive and embarrassing to the PM or undermining the PM or the government. And then the same with how we're rolling out that agenda, if it's going to hit on an agency. So, I build the relationships to know who all the key people are and then I keep those relationships up. (P08)

This individual performed the functions of an effective boundary-spanner in a networked policy environment - building relationships, communication, brokering trust and solutions and resolving real or potential conflict:

So, mostly I problem solve. I think about things that are happening and if I see gaps, I kind of stick my nose in. So, if you're an old soft-baller, like I am, in softball you'd call the position a sweeper ... And so, in softball I have a position, everyone on the field has got a position ... But we ... have a position that's called a sweeper and we can put that person out, you just need to have nine people on the ground, and that person can play anywhere. So, if the short-stop needs backing, you drop in behind there. If you need some extra work in the outfield, you can drop in there.

So, I keep an eye on that. Also, I do lots around relationship building up at Parliament; across the service and externally, so with critical stakeholders, that kind of stuff. And so, I do a lot of linking where I see those gaps. And I bring my judgement on both policy and those relationship things to how we do our business (P08).

In the following quote, the participant gives examples of what this 'sweeping' role looks like in practice:

So, last week PM's delivering the Close the Gap Report ${ }^{1}$; he wants to do the acknowledgement to the traditional owners in Noongar (language), so facilitate the relationship between, as you know I don't know if you know - then tensions around Canberra around the traditional owner stuff, so it can work those relationships. Set that stuff up, set it up with the PM, work right through that and

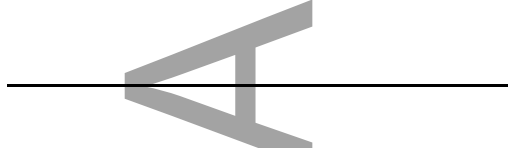

${ }^{1}$ Closing The Gap is a major initiative to address inequalities between Indigenous and non-indigenous Australians.

This article is protected by copyright. All rights reserved. 
then the PM's office sets some stuff up which antagonise the traditional owner groups; I was able to deal with that straight away in the office. So, build critical stakeholder relationships

I did a lot of time translating across the service. So, I would have reckoned my first 18 months I did lots of presentations in the department, outside the department to our colleagues in other agencies and to indigenous organisations and to others who work in Indigenous Affairs. So, I had a standard one-pager that I developed around the political landscape, the administrative landscape and the key policy things. And I did it pictorially, so people can see who's the Prime Minister, who's the minister, who's the head of the department and who's the head of Indigenous Affairs; so literally did that stuff... So, really basic things on a one-pager and I spent 18 months going out lots just to communicate stuff so that people could have some sense of knowing what was going on. (P08).

Hence, this individual fulfilled a critical role working as both an inter- and intra- departmental boundary spanner, while also managing relationships across much greater divides (i.e. politicians and community groups). With regard to the explicit aims of this paper, what is particularly interesting about this case is that it only emerged because one individual with the power and authority to design her own role saw the need. While clearly fundamental to the smooth functioning of the newly expanded PM\&C, it is a fragile arrangement. Once this individual leaves, as they are intending to do so in the near future, the position will likely dissolve. We found no indication of succession planning to support this role. This is indicative of a lack of strategic investment in boundary spanners within government, dependent instead on ad hoc arrangements.

\section{Discussion and Conclusion}

As noted at the outset of this paper, there appears to be an enduring belief that structural change can fix perennial 'boundary' problems. Yet, boundaries are not merely structural - they are also cultural and functional (i.e. people perform different jobs or functions). Placing individuals in the same organisational or departmental unit does not mean that boundaries evaporate - rather they endure and even potentially cement cultural differences as individuals become increasingly defensive. As Shields (2006) suggests, boundaries contain physical infrastructure, institutional practices and socially constructed meanings. Often, we know boundaries through their effects - as can be seen in the statements of participants in this study.

In this research we found that within the context of structural change, intra-departmental boundary spanners play an essential role, particularly in preventing dysfunctional work practices. Intra-departmental boundary spanners, in the context of PM\&C, play a delicate role they are both mechanisms of collaboration and leaders within government (Williams, 2010). In the case of central agencies, it appears that boundary spanners contribute to high quality policy advice, organisational functioning and effective government. Hence, intra-departmental boundary spanners need to be nurtured and not removed during restructuring.

This article is protected by copyright. All rights reserved. 
If boundary spanners are essential to effective working (Williams, 2013), we need to find ways to better support and nurture them. This may include the creation of dedicated roles for boundary spanners (Williams, 2013), such as the previous shadow teams that acted as a bridge between the central and line agencies. In addition, the fact that boundary spanners have unique skill-sets and competencies mean that these need to be explicitly nurtured, particularly when the achievement of outcomes relies on the ability to work across structural, cultural and/or functional boundaries. This ought to occur not just through informal mechanisms, but also formal training, mentoring and resources. Mentoring is particularly important because dealing with conflicts and working in contested cultural spaces means that boundary spanners must frequently act beyond the bounds of their formally specified role (Perrone et al., 2003). Similarly, the literature on inter-organisational boundary spanners recognises that boundary spanners face numerous complexities and role ambiguity (O'Flynn, 2011; Perrone et al., 2003; Williams, 2013, 2002). Similarly, intra-organisational boundary spanners also operate within a context of complexity and ambiguity. Importantly, the management of intra-departmental boundary spanners presents an interesting challenge given the high degrees of trust and autonomy involved (Perrone et al., 2003). Further research is needed into both the role of intradepartmental boundary spanners and how to nurture and manage their practice.

While the literature on working across boundaries within policy networks provides some clues as to how to manage boundary spanners, this is a fundamentally different context to the intradepartmental roles explored in this paper. This is critical because as we note at the outset of the paper the current changes in the Australian context point to what is potentially a fundamental shift in the role of central agencies. If this is not well managed, there will be detrimental affects for the functioning of central agencies and policy advice provided to Cabinet. Moreover, the focus on the management of policy networks has drawn our eye away from the 'center' over the last two or so decades. Our findings indicate that in studying policy networks, we cannot afford to neglect the dynamics of internal government arrangements and processes.

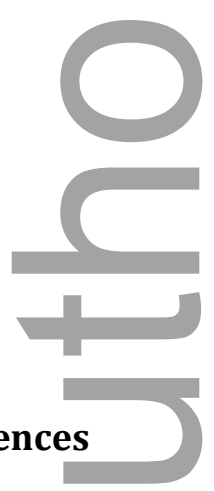

\section{References}

6, P., 1997. Holistic government. Demos, London.

Aldrich, H., Herker, D., 1977. Boundary Spanning Roles and Organization Structure. The Academy of Management Review 2, 217. doi:10.2307/257905

This article is protected by copyright. All rights reserved. 
Australian Public Service Commission, 2007. Tackling wicked problems: a public policy perspective. Australian Public Service Commission, Canberra.

Bacchi, C.L., Eveline, J., 2010. Mainstreaming politics gendering practices and feminist theory. University of Adelaide Press, Adelaide, S. Aust.

Blackman, D., 2014. The diagnostic solution?, in: O’Flynn, J., Blackman, D., Halligan, J. (Eds.), Crossing Boundaries in Public Management and Policy: The International Experience. pp. 172-189.

Blackman, D., Buick, F., Halligan, J., O’Flynn, J., Marsh, I., 2010. Australian Experiences with Whole of Government: Constraints and Paradoxes in Practice. 14th IRSPM Conference Berne, Berne, Switzerland April 7-9.

Blaikie, N., 2010. Designing Social Research, 2nd Edition. ed. Polity, MA, USA.

Boston, J., Halligan, J., 2012. Political Management and New Political Governance: Reconciling Political Responsiveness and Neutral Competence, in: Bakvis, H., Jarvis, M. (Eds.), From New Public Management to New Political Governance. McGill University Press, Montréal, Qué

Buckley, S., 2006. The Prime Minister and Cabinet. Edinburgh University Press, Edinburgh.

Carey, G., Crammond, B., 2015. What Works in Joined-Up Government? An Evidence Synthesis. International Journal of Public Administration 1-10.

doi:10.1080/01900692.2014.982292

Carey, G., Crammond, B., Keast, R., 2014. Creating change in government to address the social determinants of health: how can efforts be improved? BMC Public Health 14. doi:doi:10.1186/1471-2458-14-1087

Christensen, T., Andreas Danielsen, O., Laegreid, P., H. Rykkja, L., 2015. COMPARING COORDINATION STRUCTURES FOR CRISIS MANAGEMENT IN SIX COUNTRIES: COMPARING COORDINATION STRUCTURES FOR CRISIS MANAGEMENT. Public Administration n/a-n/a. doi:10.1111/padm.12186

Christensen, T., Laegreid, P., 2007. The whole-of-government approach to public sector reform. Public Administration Review 67, 1059-1066.

Christensen, T., Laegreid, P., 2006. The Whole of Government Approach: Regulation, Performance and Public Sector Reform., Working Paper 6. ed. Stein Rokkan Centre for Social Studies, Bergen.

Commonwealth Government, 2016. Department of Prime Minister and Cabinet.

Craig, D., 2004. Building on partnership: Sustaining local collaboration and devolved coordination. LPG Research Paper University of Auckland, Auckland.

This article is protected by copyright. All rights reserved. 
de Bruijn, J., Heuvelhof, E., 1997. Instrument for Network Management., in: Kickert, W., Klijn, E.H., Koppenjan, J. (Eds.), Managing Complex Networks: Strategies for the Public Sector. Sage, London, pp. 166-191.

Degeling, C., 1995. The significance of "sectors" in calls for urban health intersectorialism: an Australian perspective. Policy \& Politics 23, 298-301.

Dickinson, H., Carey, G., 2016. Managing and Leading in Inter-agency Settings, 2nd Edition. ed. Polity Press, Birmingham.

Dickinson, H., Sullivan, H., 2014. Towards A General Theory Of Collaborative Performance. Public Administration 92, 161-177. doi:10.1111/padm.12048

DPC, 2013. Victorian Department of Premier and Cabinet Annual Report 2012-13. State Government of Victoria, Melbourne, Vic.

Keast, R., 2011. Joined-Up Governance in Australia: How the Past Can Inform the Future. International Journal of Public Administration 34, 221-231. doi:10.1080/01900692.2010.549799

Klaster, E., 2014. Education and employment: stumbling across boundaries in the Netherlands. Crossing Boundaries in Public Management and Policy: The International Experience $229-240$.

Klijn, E.-H., 1997.An Overview, in: Kickert, W., Klijn, E.-H., Koppenjan, J. (Eds.), Managing Complex Networks: Strategies for the Public Sector. Sage, London, pp. 166-191.

Leifer, R., Delbecq, A., 1978. Organizational/environmental interchange: A model of boundary spanning activity. Academy of Management Review 3, 40-50.

LeRoux, K., 2013. 4 The boundary-spanning solution? Crossing Boundaries in Public Management and Policy: The International Experience 15, 64.

Martin, J., 1992. Cultures in organizations: Three perspectives. Oxford University Press, New York.

O'Flynn, J., 2014. Crossing boundaries: The fundamental questions in public management, in: Blackman, D., Halligan, J. (Eds.), Crossing Boundaries in Public Management and Policy: The International Experience. Routledge, London, pp. 11-44.

O’Flynn, J., 2011. Some practical thoughts on working across boundries. Occasional paper no. 14. AZSOG, Victoria, Australia.

Osborne, S. (Ed.), 2010. The New Public Governance. Routledge, New York.

Perrone, V., Zaheer, A., McEvily, B., 2003. Free to be trusted? Organizational constraints on trust in boundary spanners. Organization Science $14,422-439$.

Pollitt, C., 2003. Joined-up Government: a Survey. Political Studies Review 1, 34-49.

This article is protected by copyright. All rights reserved. 
Scharpf, P., 1989. Decision rules, decision styles and policy changes. Journal of Theoretical Politics 1, 149-76.

Schein, E.H., 1996. Three cultures of management: The key to organizational learning. MIT Sloan Management Review 38, 9.

Senate Estimates, 2013. Senate Estimates: Finance and Public Administration Legislation Committee.

Shields, R., 2006. Boundary-Thinking in Theories of the Present The Virtuality of Reflexive Modernization. European Journal of Social Theory 9, 223-237.

Strakosch, E., 2013. Will Tony Abbott be a "prime minister for Aboriginal affairs"? The Conversation September 112013.

Strauss, A., 1987. Qualitative Analysis for Social Scientists. Cambridge University Press, Cambridge.

Talbot, C., Talbot, C., 2014. The structure solution? Public sector mergers in the United Kingdom. Crossing Boundaries in Public Management and Policy: The International Experience 15, 92

Tushman, M., Scanlan, T., 1981. Boundary-spanning individuals: Their role in information transfer and their antecedents. Academy of Management Journal 24, 289-305.

Williams, P., 2013. We are all boundary spanners now? International Journal of Public Sector Management 26, 17-32. doi:10.1108/09513551311293417

Williams, P., 2010. Special agents: The nature and role of boundary spanners, in: ESRC Research Seminar Series. Collaborative Futures: New Insights from Intra and Inter-Sectoral Collaboration. University Of Birmingham.

Williams, P., 2002. The Competent Boundary Spanner. Public Administration 80, 103-124.

Yin, R., 2014. Case Study Research: Design and Methods. Sage, Thousand Oaks, CA.

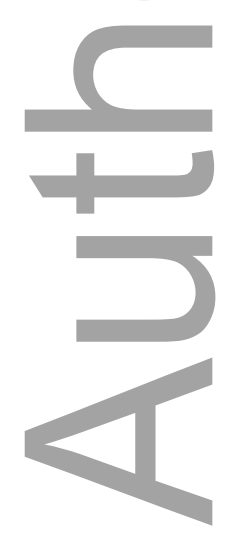

This article is protected by copyright. All rights reserved. 


\section{University Library}

\section{- M M I N E R VA A gateway to Melbourne's research publications}

Minerva Access is the Institutional Repository of The University of Melbourne

Author/s:

Carey, G;Buick, F;Pescud, M;Malbon, E

Title:

Preventing Dysfunction and Improving Policy Advice: The Role of Intra-Departmental Boundary Spanners

Date:

2017-06-01

Citation:

Carey, G., Buick, F., Pescud, M. \& Malbon, E. (2017). Preventing Dysfunction and Improving Policy Advice: The Role of Intra-Departmental Boundary Spanners. Australian Journal of Public Administration, 76 (2), pp.176-186. https://doi.org/10.1111/1467-8500.12213.

Persistent Link:

http://hdl.handle.net/11343/291715 